\section{Guidelines and Mindlines}

\author{
John Launer
}

Modern medicine is dominated by guidelines. For most doctors, hardly a day goes by without consulting a document with the latest guidance on managing one medical condition or another. At the same time, guidelines and their place in medicine are being called into question as never before. In the most downloaded article in the $B M J$ this year, for example, Trisha Greenhalgh and her colleagues offered a catalogue of the limitations of guidelines. ${ }^{1}$ These include the influence of vested interests like pharmaceutical companies that hijack the evidence 'brand' for commercial purposes, sometimes selecting or distorting research to do so. Then there is the sheer number of clinical guidelines, now so huge that a doctor who pursued all of them would have to give most patients a bucketful of medication every month, much of it in the name of preventive medicine - even though the statistically significant benefits may be marginal. Guidelines for single conditions map poorly onto complex multimorbidity, so that they are least suitable for exactly the kinds of patients who consult the most. Inflexible rules and computerised prompts have encouraged a style of medical care that is driven more by managers and finance officers than the needs and wishes of patients.

Guidelines have another limitation that possibly trumps all the others: by and large, doctors do not actually follow them. Twenty years of advice, exhortations and admonitions from the Evidence-Based Medicine (EBM) movement have failed to stamp out variation between individuals, regions or countries in the management of a wide range of conditions. It is, of course, possible to argue that we simply need more evidence, along with better guidelines. If we could persuade research scientists to be more rigorous, the argument goes, everything would be all right. We would then only need stronger incentives to make doctors compliant, and better health education to help patients make rational choices. In contrast to this view, an increasing number of critics are suggesting that the problem with guidelines is far more fundamental - the kind of problem

Correspondence to Dr John Launer, Faculty Development, Health Education England, Stewart House, 32 Russell Square, London WC1B 5DN, UK: john.launer@nwl.hee.nhs.uk that philosophers call epistemological. According to this argument, the people who inhabit EBM and generate guidelines - the researchers, policy makers, managers and doctors - are living in a kind of intellectual bubble, where they recognise only certain types of knowledge and practice as valid, and discount anything that does not fit with their world view.

\section{KNOWLEDGE IN PRACTICE}

Two British health researchers have been particularly vigorous in putting forward this case. In 2004, John Gabbay and Andrée Le May published a critique of "the over-rationalist model implicit in evidence based health care". ${ }^{2}$ They looked at the way EBM emphasises academic research, and contrasted this with business and industry, where people pay far more attention to so-called "tacit knowledge" or "knowledge in practice". This is the kind of knowledge that emerges when you test out solutions in the real world of complex human systems, rather than relying on simplified trials, abstracted from their original context. Gabbay and Le May argued that EBM undervalued such tacit knowledge, promoting naïve "cookbook" practice instead. They pointed out how attempts to change clinical practice often founder because of local contexts, including organisational ones. They accused the EBM movement of ignoring evidence from psychologists about the useful role of professional shortcuts in professional decision-making, including "scripts," "heuristics," and "rules of thumb".

Gabbay and Le May based their case on their own ethnographic research. They observed a group of highly regarded general practitioners (GPs) in a range of encounters, including consultations, home visits, and informal and formal meetings. This showed that experienced clinicians rarely use explicit evidence from research. Instead, they rely on what Gabbay and Le May call "mindlines". These are "collectively reinforced, internalised, tacit guidelines", developed through clinicians' own experience and that of their colleagues, as well as interactions with opinion leaders, patients, pharmaceutical representatives and others. Such mindlines are continually negotiated with key professional contacts, through a range of informal interactions. They are adapted in the face of changing organisational demands, resulting in individual and collective forms of "knowledge in practice". This is what enables doctors to answer questions like: "How do I manage this specific patient, at this exact moment, in these particular circumstances, and within my own organisation, health system, and culture?"

Following their initial work, Gabbay and Le May continued their research into mindlines, both in primary and secondary care. In 2011, they published a book with the intentionally paradoxical title: "Practice-Based Evidence for Healthcare: Clinical Mindlines". 3 "Textbooks, expert systems and guidelines", they wrote, "cannot help very much when a busy clinician is making decisions that need to resolve conflicting goals such as weighing financial costs against health benefits against managerial targets, all the while applying probabilistic science to individuals, and simultaneously handling all the people, with their differing needs and demands, who are involved in optimally managing an illness". They proposed that mindlines, by contrast, allow for "considerable plasticity and elasticity for adaptation to individual patients and circumstances...[They] draw the boundaries around what is acceptable with regard to both the knowledge and the values that the clinician brings to bear in every decision they make". They found theoretical backing for their approach from fields as diverse as learning theory, knowledge management and narrative medicine. In a striking comparison, they likened mindlines to the songlines of Australian aboriginals: "the labyrinth of 'invisible pathways' ... writhing this way and that, consisting of stories that guide a person's wanderings across the Outback".

\section{DIFFERENT PARADIGMS}

The concept of mindlines has become influential among some academics, but it has not had the impact elsewhere that it deserves. In a systematic review of papers referring to mindlines, Wieringa and Greenhalgh recently traced 340 articles published over the last decade, but found that over a third of these took a naïve or simplistic view, often just comparing mindlines with the assumed superiority of traditional guidelines. ${ }^{4}$ A further group of papers used the term mainly as shorthand for "consulting with colleagues". Fewer than one in five engaged with mindlines as a theoretical or philosophical concept, linking them to other fields where people view the world in different ways to the biomedical one. Commenting on this, 
Wieringa and Greenhalgh quote the scientific philosopher Thomas Kuhn: "The proponents of different paradigms practice their trades in different worlds". However, there were also some exceptional papers that grasped the concept fully and developed it further. These included an article from Ghana, looking at how decisions are made in frontline maternity and newborn services. ${ }^{5}$ Its authors noted how the mindlines of healthcare workers interact with so-called "client lines", related to the preferences and pressures of clients, their families and community, including their social, religious and cultural values and beliefs. This is a helpful reminder that knowledge creation and dissemination occurs among networks of patients, just as it does among professionals, and this needs to be taken into account as well.

None of these writers claim that mindlines are intrinsically accurate or selfcorrecting. Nor do they allege that guidelines are always useless or harmful. Both guidelines and mindlines can point in the direction of truth, or lead people astray. The case for mindlines is a subtler one: we always need to take account of human and social contexts in our approach to evidence. As Gabbay and Le May state: "All knowledge, including clinical knowledge, is a social construction, and all observations, including scientific ones, are theory laden." We need biomedical science in order to practise logically and ethically, but we should use this dialectically together with a constructionist view. ${ }^{6}$ We should acknowledge this more openly, and put as much effort into discovering how mindlines work, as we do into the production of guidelines. It is only by using both perspectives, and judging each in the light of the other, that we can navigate our way forward as practitioners, and have balanced encounters with patients.

Twitter Follower John Launer at @JohnLauner

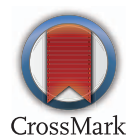

To cite Launer J. Postgrad Med J 2015;91:663-664.

Postgrad Med J 2015;91:663-664.

doi:10.1136/postgradmedj-2015-133766

\section{REFERENCES}

1 Greenhalgh T, Howick J, Maskrey N for the Evidence Based Medicine Renaissance Group. BMJ 2014;348: g3725.

2 Gabbay J, Le May A. Evidence based guidelines or collectively constructed "mindlines"? Ethnographic study of knowledge management in primary care. BMJ 2004:329:1249-52.

3 Gabbay J, Le May A. Practice-Based Evidence for Health Care: Clinical Mindlines. Abingdon, UK: Routledge, 2011.

4 Wieringa S, Greenhalgh T. 10 years of mindlines: a systematic review and commentary. Implement Sci 2015;10:45.

5 Oduro-Mensah E, Kwamie A, Antwi E, et al. Care decision making of frontline providers of maternal and newborn health services in the greater Accra region of Ghana. PLoS One 2013;8:e55610.

6 Launer J. 'You're the doctor, Doctor': Is social constructionism a useful stance in general practice consultations? J Fam Ther 1996;18:255-67. 